\title{
On Viewing a Portrait by Otto Dix
}

A broad schmiss across his cheek, full lips, pursed as if to suppress a smile,

Dr. Hans Koch wears pince nez, a white coat, collar up, sleeves rolled to the elbows.

Standing by a chair with metal stirrups, a white tiled room, instruments scattered on a nearby table, he waits a tourniquet in one hand, glass syringe in the other, its long needle facing me.

And I am twelve once again, as my father looks up, a syringe in his hand when I come in, back from a ball game, his black bag open on the kitchen table.

"This is for you! There's a polio epidemic. You need gamma globulin, 5 cc in each butt."

He took care of us all. I hated his office, the pungent smells, bright examination light, the stranger he became with his white coat, his mirrored monocle through which he gazed at me.

"Stop whining," as he filled the syringe.

"You need this. Let's get on with it!"

\section{Richard Bronson}

Correspondence to Richard Bronson, Department of Obstetrics \& Gynecology, Stony Brook University Medical Center, T9-080, Stony Brook, New York, 11794-8091, USA; Richard.Bronson@Stonybrookmedicine.edu

Competing interests None declared.

Provenance and peer review Not commissioned; internally peer reviewed.

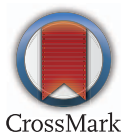

To cite Bronson R. Med Humanit 2017:43:e18.

Published Online First 24 January 2017

Med Humanit 2017;43:e18. doi:10.1136/medhum-2016-011160 